\title{
A CONCEPÇÃO GEOGRÁFICA DA SOCIEDADE HUMANA: UM DEPOIMENTO (*).
}

\section{EDUARDO PAZERA JUNIOR \\ da Universidade Federal da Paraiba.}

\section{1. - Introdução: As Fontes.}

Não com o intuito de servir de provável roteiro a algum hipotético leitor, mas sim, apenas para registrar a linha de pensamento do autor deste ensaio, mencionaremos algumas fontes bibliográficas.

No que se refere ao conteúdo mais intrinsecamente "histórico" deste tema, o autor deve muito de sua formação ao mestre Aroldo de Azevedo (a quem muito apreciaria render as devidas homenagens), não só através de suas preleções, mas também, no que se refere à evolução do pensamento geográfico, ao pequeno-grande livro intitulado $O$ Mundo Antigo. Muito devemos também à leitura da edição lusitana de CLOZIER ( As etapas da Geografia). Algo aprendemos, ainda, folheando KRETSCHMER na sua edição espanhola sobre a História da Geografia .

$\mathrm{Na}$ parte metodológica (contudo, com valiosíssimas contribuições à História do pensamento geográfico) foi-nos de suma utilidade, e também de agradável deleite, o Espírito e Propósito da Geografia dos britânicos WOOLDRIDGE \& EAST. Os autores, ainda que por vezes assumam posições discutíveis ("superadas", segundo HARTSHORNE), contribuem para libertar o geógrafo de certos complexos de inferioridade ...

(*). - Dedicado à memória do Prof. Aroldo de Azevedo.

Nota - O presente "ensaio" resultou, com algumas modificaçôes; do manuscrito elaborado para atender a uma das questōes da prova de seleção, realizada em feveieiro de 1974, para ingresso no Curso de Pós-Graduação em Geografia (Área de Geografia Humana) da Faculdade de Filosofia, Letras e Ciências Humanas da Universidade de São Paulo. O tema foi determinado pelo examinador, o Prof. Dr. Manoel Seabra. Contudo, os conceitos aqui emitidos são de exclusiva responsabilidade do autor. 
Faz já uma década, tivemos a injeção de otimismo - "la joie de connaître" - de CHOLLEY com seu Guide de l'étudiant.

MONBEIG também nos influenciou, não só através de algumas preleções que assistimos mas também pela consulta de trechos de Pioniers et Planteurs de l'Etat de São Paulo, e do Papel e Valor do Ensino da Geografia e de sua Pesquisa ...

De PIERRE GEORGE, um dos autores a quem mais devemos nossa formação, interessando ao presente tema saliente-se: Os Métodos da Geografia.

Leitura recente, ainda não bem refletida e sedimentada, é a obra de R. HARTSHORNE, na edição do IPGH, Questões sobre a $\mathrm{Na}$ tureza da Geografia. Obra de fôlego, muito acessível e freqüentemente dotada de uma amarga ironia (fruto dos practical jokes norte-americanos?) .

Finalmente, deixamos de mencionar a influência dos ensinamentos que recebemos de nossos professores da Universidade de São Paulo. Enfatizamos o nome do Prof. Aroldo de Azevedo sobretudo por não pertencer mais àquela casa .

\section{2. - A Evolução da Concepção Geográfica da Humanidade.}

Em certo sentido, o homem tem pensado em termos geográficos desde os primórdios da humanidade. Assim sendo, sempre houve uma determinada abordagem geográfica da sociedade humana, pelo simples fato dela estar situada na superfície terrestre.

Pelo que transparece das obras dos autores que se ocuparam com a evolução do pensamento geográfico, as primeiras concepções de índole geográfica da sociedade dão ênfase à fragilidade do homem perante a Natureza. Essa concepção é evidente não só nos escritos de caráter "geográfico". A obra de HOMERO, por exemplo, denota claramente essa concepção. A poesia de CAMỖES (abeberada nos clássicos) enfatisa a fragilidade đesse "bicho da terra tão pequeno" perante a "Fera Natura". As grandes navegações portuguesas muito contribuíram para a ampliação do horizonte geográfico da humanidade. Assim, os novos conhecimentos desmitificaram os "mares nunca dantes navegados".

Contudo, de forma nem sempre clara, mas, em todo caso, subjacente nos escritos ("científicos" ou não) produzidos até o século XVIII, a sociedade humana é encarada como frágil competidora da Natureza . 
Tudo indica que, a partir desse período (provavelmente em função do pensamento racionalista e das novas conquistas tecnológicas que culminarão na Revolução Industrial), essa tendência passa a ganhar novos rumos que, posteriormente, irão, por contradição sutil, conduzir à idéia do determinismo geográfico .

No referido século, lembremos a título de ilustração, Kant (hoje só conhecido como filósofo), titular da cadeira de "Geografia Física" na Universidade de Koenigsberg, incluía nas suas preleçôes alguns capítulos sobre a "sociedade humana". HARTSHORNE, comentando o pensamento geográfico de KANT, esclarece que tal procedimento era normal na época, pois o homem passara a ser considerado parte da Natureza (sendo "Física" o estudo das "leis" da Natureza).

Fato curioso é que, apesar das contínuas e crescentes conquistas do homem sobre a natureza, patentes, notadamente, com a Revolução Industrial, desenvolvem-se, progressivamente, idéias em termos de dependência estrita do homem em relação aos ditames do meio natural. Em grande parte devido aos progressos metodológicos das ciências naturais, essas concepções vão ganhando corpo até a sua culminância na corrente determinista alemã. $O$ maior expoente, no século XIX, será RATZEL.

O determinismo geográfico, embora aspirasse ser a visão mais "científica" de uma abordagem geográfica da sociedade humana, vai cair em freqüentes posições dogmáticas e, até mesmo, idealistas. Estas últimas são bem patentes na obra de RITTER, que em tudo vê o "plano divino".

Opondo-se à corrente determinista, por vezes de forma excessivamente virulenta, surge o possibilismo da escola francesa. $\mathrm{Na}$ verdade, os possibilistas vão, às vezes, acusar os deterministas de "pecados" que nem sempre eles haviam cometido... Há que entender tal hostilidade (ao nosso ver) num contexto mais amplo que transcende à polêmica científica. Estamos nos referindo à rivalidade franco-germânica, não só no plano filosófico (leia-se ideológico), mas também no âmbito econômico e militar.

Não estarão as diatribes dos geógrafos franceses contra seus confrades germânicos em alguma relação com a humilhação nacional de 1870? Seria uma manifestação, nem sempre consciente, de revanchismo?

Importa frisar que a escola determinista, pontificada notadamente por $P$. VIDAL DE LA BLACHE, dá ênfase às "possibilidades" de escolha por parte da sociedade de seus genres de vie, em su- 
ma, confere-se um alto grau de livre-arbítrio, dentro de certas limitaçōes. A natureza é, assim, domada pelo homem de acordo com o equipamento técnico-cultural disponível e de acordo com a capacidade e interesses das sociedades, respeitadas certas limitações de natureza.

\section{3. - Alguns Aspectos da Atual Visão Geográfica da Socieda- de Humana.}

Faz quase duas décadas que vários autores (como HARTSHORNE e WOOLDRIDGE \& EAST), salientam que o debate determinismo versus possibilismo está superado.

A dupla britânica (WOOLDRIDGE \& EAST), julga que, não obstante, num certo sentido, a Geografia possui um certo caráter determinista, na medida que procura (inter alia) estudar as relações terra-homem. Inclusive (para eles) os estudos geográficos devem começar pela base, que é a terra.

Já o autor de Perspectives on the Nature of Geography comenta que nem o determinismo é mais "puro", nem tampouco o possibilismo ... A título de exemplo, HARTSHORNE comenta o néo-determinismo de G. TAYLOR (stop and go determinism), que não é mais "aquele". Aliás, ironicamente, parece que nem sequer RATZEL teria sido determinista "puro"!

De acordo com a formação do autor dessas linhas, a abordagem geográfica atual da sociedade humana, deve tomar como ponto de partida a ação do homem como organizador do espaço.

E a sociedade humana que cria quadros diferenciados na superfície da terra, mesmo quando esses quadros tenham sido relativamente uniformes antes da intervenção humana. E pois a ação humana que estrutura a paisagem terrestres, seja pela ação do Homo faber, ou (por que não?), do Homo ludens.

Qualquer que seja o método empregado para o estudo geográfico do homem, esse deve ser, na nossa Weltanschauung, a perspectiva filosófica norteadora da Geografia (sem epítetos - Geografia tout court).

Parece-nos que é válido utilizar tanto o método "sistemático" (ou "tópico", como diz HARTSHORNE) como o "regional". Não há dicotomia entre a Geografia Geral e a Regional e sim, apenas, diferentes escalas de enfoque. Na realidade, uma não pode existir sem a outra. Além disso, de certa maneira todo estudo geográfico é "regional" na medida que se situa no espaço e é "sistemático" na medida que está inserido em um amplo contexto de fenômenos que se inter-relacionam e interinfluenciam. 
Finalmente, à guisa de justificativa, vale dizer que o fato de escrevermos, nas linhas anteriores, que há que tomar como ponto de partida a ação do homem como organizador do espaço, não implica na excessiva valorização do homem em detrimento do espaço (no caso, a superfície terrestre) .

Embora o autor seja um ardente (não tanto quanto o deseja) defensor de uma concepção antropocêntrica da Geografia, não se deve esquecer que a Geografia é, antes de mais nada, uma "ciência dos lugares", no conceito imortal de LA BLACHE. Nesses termos, há que estudar os "lugares" obrigatoriamente (embora nem sempre, inicialmente - como era de uso no passado) sob o ponto de vista, também, da natureza (através da chamada - não muito adequiadamente - Geografia Física), para que possamos compreender a "terra como morada do homem" e o "homem como estruturador da terra".

A compreensão dessas inter-relações, não dicotômicas, natureza-homem e homem-natureza, dentro de um todo harmônico e coerente (fruto da abordagem científica da Geografia), proporciona, não só, satisfação intelectual ao estudioso, mas também, pode contribuir para o bem estar da sociedade humana que habita (provisoriamente?) este pequeno planeta.

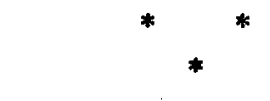

\section{BIBLIOGRAFIA CITADA}

AZEVEDO (Aroldo de) ( (1965) - O Mundo Antigo: expansão geográfica e evolução da Geografia. São Paulo, DESA e Editora da Universidade de São Paulo.

CHOLLEY (Andrě). (1951) - La Géographie, guide de l'etudiant. Paris, Presses Universitaires de France.

GEORGE (Pierre) . (1972) - Os métodos da Geografia. São Paulo, Difusão Européia do Livro.

HARTSHORNE (Richard) . (1969) - Questões sobre a natureza da Geografia .

Rio de Janeiro, Instituto Panamericano de Geografia e História.

KRETSCHMER (Konrad). (1942) - História de la Geografia. 3a ed., Barcelona, Labor.

MONBEIG (Pierre). (1952) - Pionniers et Planteurs de São Paulo. Paris, Armand Collin.

(1957) - Novos Eśtudos de Geografia Humana Brasileira. São Paulo, Difusão Européia do Livro.

WOOLDRIDGE (S. W.) \& EAST (W. G.). (1967) - Espírito e Propósito da Geografia. Rio de Janeiro, Zahar. 